\title{
DMF-T ile Dental Anksiyete Arasındaki İlişkinin İncelenmesi: Dicle Üniversitesi Örneği
}

\author{
Elif Pınar BAKIR [0] ${ }^{1}$, Simge GÜMÜŞ [ ${ }^{1}$, Şeyhmus BAKIR ${ }^{1}$
}

Öz

Amaç: Dental anksiyete, diş hekimliği uygulamalarına bağlı gelişen streslerin bireyde yarattığı tepki olarak ifade edilmektedir. Dental anksiyeteli bireyler, randevularını erteleyerek geciktirmekte ve hatta diş hekiminden tamamen kaçınmaktadır. Çalışmamızda; Dicle Üniversitesi Diş Hekimliği Fakültesi’ndeki öğrencilerin diş sağlığı ile dental anksiyete arasındaki ilişkinin incelenmesi amaçlanmıştır.

Gereç ve Yöntemler: Çalışmaya Dicle Üniversitesi Diş Hekimliği Fakültesi’nden 300 öğrenci dâhil edildi. Katılan öğrencilerin ağız muayeneleri yapılarak, DSÖ’nün diş sağlığı durumunu değerlendirmekte belirlediği DMF-T indeksi kullanılarak hesaplandı. Öğrencilere dental işlemlere karşı anksiyete seviyelerini ölçebilmek için 5 sorudan oluşan Modifiye Dental Anksiyete Skalası (MDAS) anketi uygulandı. MDAS sonuçları $\geq 19$ olan bireyler yüksek anksiyeteli olarak düşünüldü. Bireylerin demografik niteliklerini de içeren veriler istatistik programına aktarılarak değerlendirildi. Bulgular: Erkeklerin MDAS değerleri kadınlara göre anlamlı derecede düşüktür. Yaş grupları arasında DMF-T değerleri bakımından anlamlı farklılık bulunmaktadır. 17-20 yaş aralığındaki katılımcıların DMF-T değeri 26-30 yaş aralığındakilere oranla anlamlı derecede düşük hesaplanmıştır.

Sonuç: DMF-T değerleri üst sınıflara gidildikçe, anksiyete verilerinden bağımsız olarak artmıştır. Araştırmamızdan elde edilen diğer verilere göre; kadın katılımcılar erkeklere nazaran anlamlı derecede yüksek anksiyeteye sahip bulunmuştur. Cinsiyet ve sınıftan bağımsız olarak Diş hekimliği eğitiminin erken bir aşamasında müfredata eklenebilecek 'anksiyete tanı ve kontrol yöntemleri'" üzerine bir eğitimin kaygıyı azaltmada yardımcı olacağını düşünmekteyiz.

Anahtar Kelimeler: Dental anksiyete; diş hekimliği öğrencisi; DMF-T indeksi

\section{Examination of the Relationship between DMF-T and Dental Anxiety: The Case of Dicle University}

\section{ABSTRACT}

Aim: Dental anxiety is the reaction caused by the stresses in patient a specific condition that develops due to treatment. Individuals who have this anxiety delay their appointments or even avoid the dentist completely. It was purposed to examine relationship between dental health and anxiety grades of students studying at Dicle University Faculty of Dentistry.

Material and Methods: 300 students from Dicle University Faculty of Dentistry were included in this study. It was calculated using the DMF-T index determined by the WHO to evaluate the dental health by performing examinations of the individuals. The Modified Dental Anxiety Scale (MDAS) questionnaire consisting of 5 questions was applied to the students to measure anxiety. MDAS scores $\geq 19$ were considered to have high anxiety. The data including demographic characteristics were transferred to the statistics program and evaluated.

Results: MDAS of men is significantly lower than women. There is a significant difference between age groups in terms of DMF-T values. The DMF-T value of those between the ages of 17-20 is significantly lower than between the ages of 26-30.

Conclusion: DMF-T values increase as the upper classes are attended, regardless of the anxiety data. According to other data from our research; female students were found to have significantly higher anxiety than male students. As regardless of gender and class; we think that a training on "anxiety diagnosis and control methods" that can be added to the curriculum at early stage of dentistry education will help reduce anxiety levels.

Keywords: Dental anxiety; dental students; DMF-T index.

1 Dicle Üniversitesi Diş Hekimliği Fakültesi Restoratif Diş Tedavisi Ana Bilim Dalı, Diyarbakır,Türkiye

*Bu çalışma, 19-21 Şubat 2021tarihleri arasında Rize'de düzenlenen Karadeniz Zirvesi 5. Uluslararası Uygulamalı Bilimler kongresinde sözlü bildiri olarak sunulmuştur.

Sorumlu Yazar / Corresponding Author: Simge GÜMÜŞ, e-mail: dtsimgegumus@gmail.com

Geliş Tarihi / Received: 03.03.2021, Kabul Tarihi / Accepted: 15.06.2021

Düzce Üniversitesi Sağlık Bilimleri Enstitüsü Dergisi 2021; 11(3): 312-317 


\section{GíRiş}

Davranış bilimi alanının konusu olan, korku ve anksiyete terimleri oldukça ilişkili olup literatürde sıklıkla birbirinin yerine kullanılmaktadır. Bu sebeple, korku ile anksiyete arasında sağlıklı bir ayrım yapılmalıdır. Korku öznel bir his olup, bilinen bir tehlikeye karşı gösterilen fizyolojik, davranışsal ve duygusal bir tepki olarak tanımlanırken, anksiyete ise zararsız durumlar tarafindan da tetiklenebilen kişilik bütünlüğünün tehdidi durumunda görülen, korkunun daha geniş kapsamlı ve bilinmeyene karşı gelişen şekli olarak tanımlanmaktadır (1-3).

Yapılan araştırmalar dental anksiyetenin, diş tedavisini erteleme ya da tedaviden kaçınma konusunda esas rol oynadığını göstermiştir (2). Bu konu üzerinde çalışmalar yapan araştırmacılar, anksiyeteden dolayı dental işlemlerden kaçınan bireylerin ağız ve diş sağlığının kötüye gittiğini gösteren sikluslar tanımlamıştır $(4,5)$. Neredeyse tüm toplumlarda yaygın bir sorun olarak karşımıza çıkan dental anksiyeteye bağlı olarak, yetişkin bireylerin İngiltere'de \%25, Avustralya'da \%16, Amerika Birleşik Devletleri'nde \%20 'sinin dental işlemleri geciktirdiği bildirilmiştir (6-8). Yapılan benzer çalışmalarda bu oranın Türkiye'de \%21,3 ile \%23,5 değerleri arasında olduğu ifade edilmiştir $(9,10)$.

Dental anksiyeteye sebep olabilecek faktörlerin araştırıldığı güncel çalışmalar kapsamında; hastanın cinsiyeti, yaşı, travmatik dental tecrübeleri, eğitim durumu ve yaşadığı ortamın etkili olduğu belirtilmiştir (11-14). Cinsiyet ile anksiyete korelasyonunu araştıran çalışmalarda kadınların daha yüksek oranda dental anksiyete yaşadıkları bildirilirken; yaş ile anksiyete ilişkisinin incelendiği araştırmaların sonucunda yaş artışına bağlı olarak anksiyete düzeyinde azalma görüldüğü ifade edilmiştir $(2,15)$. Travmatik dental tecrübeler, anksiyetenin en önemli nedenlerinden biridir. $\mathrm{Bu}$ tür deneyimlere sebep olan etkenler; ağrılı dental işlemler, olumsuz bilişsel fonksiyonlar ve artan ağrı algısı ile ilintilidir (16). Çocukluk döneminde yaşanan travmatik diş hekimi öyküsü, bireyin anksiyete eğilimi, ailenin dental tedavi bilinç düzeyi ve yaklaşım şekli ile sosyal çevre faktörleri anksiyete gelişiminde önemli etkenlerdir (17). Eğitim düzeyi ile anksiyete korelasyonunu inceleyen çalışmalar sonucunda; eğitim düzeyi düşük olan bireylerde daha yüksek oranda anksiyete görülmüştür $(13,18)$. Yapılan kapsamlı bir literatür taraması ile, çeşitli üniversitelerin lisans öğrencileri arasında dental anksiyete yaygınlığının \%11 ile \% 27,5 arasında değiştiği sonucuna ulaşılmıştır (1921).

Dental anksiyete sadece hastalar için değil, diş hekimleri için de tedavi etme konusunda büyük bir endişe kaynağıdır. Tedavi prosedürlerini uygulayan diş hekimlerinde de artmış kan basıncı, yüksek kalp hızı gibi fizyolojik stres göstergelerinin hastalardan elde edilen değerlerle eşit olduğunu gösteren çalışmalar bulunmaktadır (22).

Diş hekimliği fakültesi öğrencileri, gelecekte sağlık hizmetlerinin önemli bir bölümünü oluşturacaklardır (23). $\mathrm{Bu}$ nedenle, bu öğrencilerin bireysel anksiyetelerinin üstesinden gelmelerine yardımcı olabilecek teknikleri öğrenmeleri gerekmektedir. Anksiyete düzeylerindeki azalma, bu öğrencileri hastalarını daha iyi tedavi edebilen özgüvenli klinisyenler yapacaktır. Planladığımız bu çalışmada; Dicle Üniversitesi Diş Hekimliği Fakültesi'nde öğrenim gören öğrencilerin dental aksiyete düzeylerinin tespiti ve ağız diş sağlığı ile dental anksiyete düzeyleri arasındaki ilişkinin incelenmesi amaçlanmıştır.

\section{GEREC VE YÖNTEMLER}

Çalışmamıza 2019-2020 eğitim döneminde Dicle Üniversitesi Diş Hekimliği Fakültesi'nde eğitimlerine devam eden I, II, III, IV ve V. Sınıf öğrencileri dahil edilmiştir. Dicle Üniversitesi Diş Hekimliği Fakültesi Etik Kurulunun aldığı etik kurul kararıyla (protokol no: 2019/14 ) yapılmıştır. Anketler uygulanmadan önce, katılımcılara çalışmanın amacı ve kapsamı anlatılmış olup aydınlatılmış onamları alınmış; sonrasında anketler dağıtılmıştır. Çalışmamıza gönüllü olarak dahil olan bireylere birer adet anket formu dağıtılarak cevaplamaları istenmiştir. Çalışmada, her öğrenci ile yüz yüze görüşülmüş, anketler aynı gün içerisinde doldurulup tarafimıza teslim edilmiştir.

Katılımcı bireyler anketleri cevapladıktan ve teslim ettikten sonra, tecrübeli iki hekim tarafından, ünit 1şı̆̆ı altında, sond ve ağız aynası yardımıyla, dişler kurutularak Dünya Sağlık Örgütü'nün (WHO) teşhis kriterlerine uygun klinik olarak muayene edilmiştir. Klinik muayenede kesin çürük belirtisi bulunan dişler çürük olarak, restorasyon bulunan dişler dolgu olarak, çürük sebebiyle çekilmiş olan dişler eksik olarak kabul edilmiştir. Dünya Saglık Örgütü tarafından ağız-diş sağlığı belirleyici kriteri olarak kabul edilen çürük ( $\mathrm{D}=$ Decay), eksik ( $\mathrm{M}=$ Missing) ve dolgulu ( $\mathrm{F}=$ Filled) dişlerin belirlendiği DMFT indeksi, her bir katılımcı için bireysel olarak belirlenmiştir. Anket formlarında T.C kimlik numarasının ilk altı hanesinin istenme sebebi olası tekrarları engellemektir.

\section{İstatistiksel Analiz}

İstatistiksel analizde Kolmogorov Smirnov veya Shapiro Wilk's' den yararlanılarak, değişkenlerin normallik testi sonuçları incelenmiştir. İstatistiksel değerlendirmede anlamlılık düzeyi 0,05 olarak belirlenmiş, $\mathrm{p}<0,05$ ise değişkenlerin normal dağılmadığı kabul edilmiştir. Mann Whitney U ve Kruskal Wallis H Testleri ve Post-Hoc testleri yardımıyla grupların farklılık değerlendirmesi yapılmıştır. Verilerin ölçme düzeyine göre aralarındaki ilişki incelenirken korelasyon testinden yararlanılmıştır. Anlamlılık düzeyi olarak 0,05 değeri kullanılmış ; $p<0,05$ ise anlamlı bir ilişkinin olduğu, $p>0,05$ olması durumunda ise anlamlı bir ilişkinin olmadığı belirtilmiştir. Elde edilen veriler tanımlayıcı istatistik, Mann Whitney U ve Ki- kare / Fisher's exact testleri ile analiz edilmesi planlanmıştır. Uygulanan anket formlarının bir örneği aşağıda sunulmuştur.

Modifiye dental anksiyete skalasinda (MDAS) her soru skor değeri 1-5 arasında, toplam skor değerleri ise 5-25 puan aralığında değişmektedir. MDAS skor toplamı 5 olan katılımcıların(M1) dental anksiyetesi bulunmadığı kabul edilmektedir MDAS skor toplamı 5-19 puan arasında olan katılımcılar(M2) düşük-orta anksiyeteli bireyler olarak tanımlanmıştır. MDAS skorları için eşik değeri 19 olarak belirlenmiş olup, 19 puan ve üzeri skora sahip katılımcılar(M3) ise yüksek anksiyeteli bireyler olarak tanımlanmıştır. Ankete katılan bireylerin MDAS skorları ve MDAS değerleri gruplandırılarak ayrı ayrı incelenmiştir. 
Modifiye Dental Anksiyete Skalası (MDAS) formu

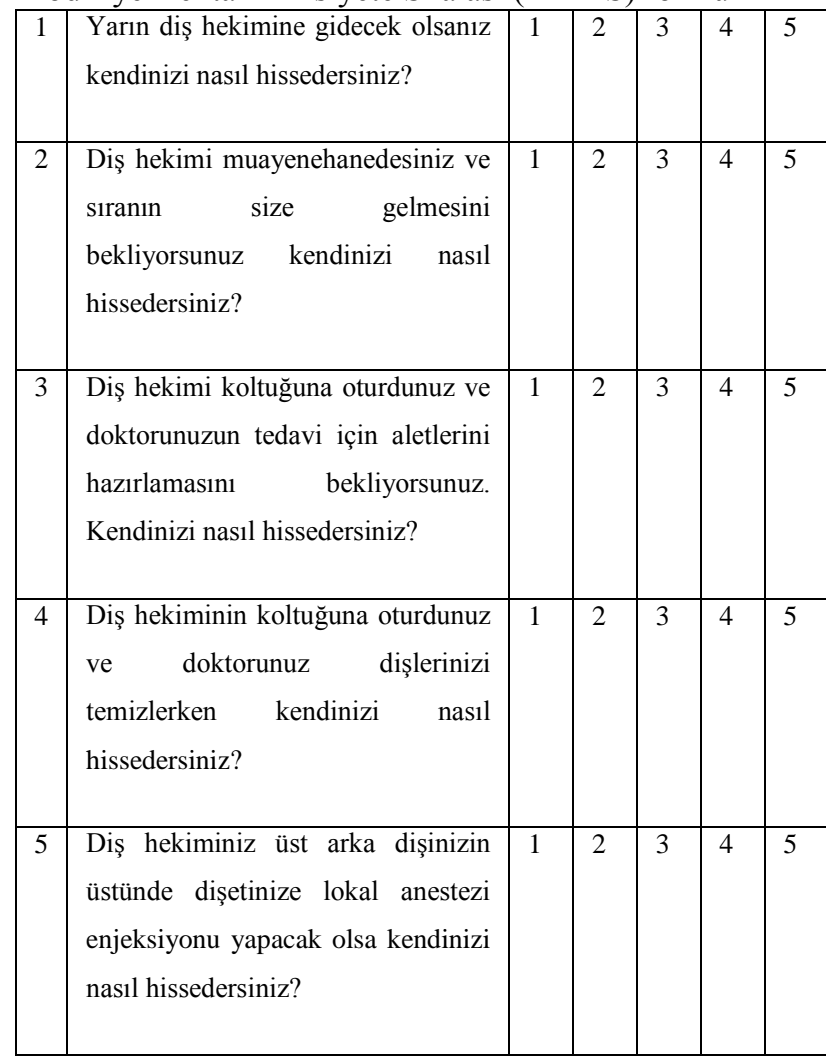

1: Hiç endişelenmem 2: Biraz endişelenirim 3: Endişelenirim 4: Çok endişelenirim 5: İleri derecede endişelenirim

\section{BULGULAR}

Çalışmaya katılan bireylerin 100 (\%33)'ü $17-20$ yaş arasında, 186 (\%62)'sı 21-25 yaş arasında ve $14(\% 4,7)$ ü 26-30 yaş arasındadır. Çalışma 123 (\%41) kadın ve 177 $(\% 59)$ erkek ile gerçekleştirilmiştir.

Sınıflar incelendiğinde katılımcıların $40 \quad(\% 13,3){ }^{\prime} 11$. Sinıf, 73 (\%24,3)’ü 2.sınıf, $47(\% 15,7)$ 'si 3. Sinıf, 66 (\%22)'sı 4. Sinıf ve $74(\% 24,7) ’ \ddot{\text { ù }}$ ise 5. Sınıf şeklinde dağılım göstermiştir. MDAS sınıfları incelendiğinde ise en fazla katılımcı sayısı $266(\% 88,67)$ ile M2 düzeyinde (5-19 puan aralığında) olduğu görülmüștür (Tablo 1).

Tablo 1. Frekans dağılım tablosu $(n=300)$

\begin{tabular}{|c|c|c|c|}
\hline & & $\mathbf{n}$ & $\%$ \\
\hline \multirow{3}{*}{ Yaş } & 17-20 arası & 100 & 33,3 \\
\hline & $21-25$ arası & 186 & 62 \\
\hline & 26-30 arası & 14 & 4,7 \\
\hline \multirow{2}{*}{ Cinsiyet } & Kadın & 123 & 41 \\
\hline & Erkek & 177 & 59 \\
\hline \multirow{5}{*}{ Sinif } & 1 & 40 & 13,3 \\
\hline & 2 & 73 & 24,3 \\
\hline & 3 & 47 & 15,7 \\
\hline & 4 & 66 & 22 \\
\hline & 5 & 74 & 24,7 \\
\hline \multirow{3}{*}{ MDAS SINIF } & M1 (5 ve daha az) & 19 & 6,3 \\
\hline & M2 (5-19 arası) & 266 & 88,7 \\
\hline & M3 (19 ve daha fazla) & 15 & 5 \\
\hline
\end{tabular}

MDAS: Modifiye dental anksiyete skalas1

Modifiye dental anksiyete skalası değerleri açısından cinsiyet değişkeni yönünden istatistiksel olarak anlamlı farklılık bulunmaktadır $(\mathrm{p}=0,006)$. Erkek bireylerin Modifiye dental anksiyete skalası skor değerleri kadın bireylere göre anlamlı derecede düşüktür. (Tablo 2, şekil 1)

\section{Modifiye dental anksiyete skalası}

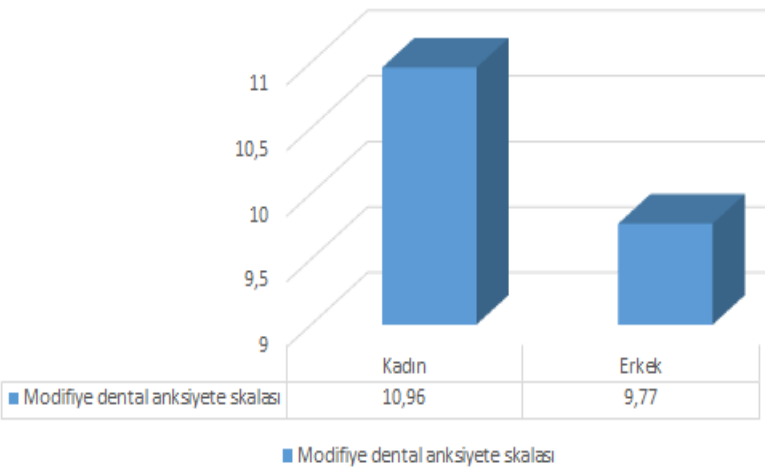

Şekil 1. Modifiye dental anksiyete skalası değerleri bakımından cinsiyetlere göre dağılım

Tablo 2. Modifiye dental anksiyete skalası değerleri bakımından cinsiyetler arasındaki farklılığa ilişkin analiz sonucu

\begin{tabular}{|c|c|c|c|c|c|c|c|}
\hline \multicolumn{2}{|c|}{} & \multicolumn{3}{|c|}{$\begin{array}{c}\text { Modifiye dental anksiyete } \\
\text { skalas }\end{array}$} & \multicolumn{2}{|c|}{ Analiz sonucu } \\
\cline { 2 - 6 } & $\mathbf{n}$ & Median & Min & Max & z & p \\
\hline \multirow{4}{*}{ Cinsiyet } & Kadın & 123 & 11 & 5 & 24 & & \\
\cline { 2 - 6 } & Erkek & 177 & 10 & 5 & 22 & \multirow{2}{*}{$-2,729$} & $\mathbf{0 , 0 0 6}$ \\
\cline { 2 - 6 } & Total & 300 & 10 & 5 & 24 & & \\
\hline
\end{tabular}

Modifiye dental anksiyete skalası değerleri bakımından farklı yaşlardaki bireyler arasında istatistiksel olarak anlamlı farklılık bulunmamaktadır $(\mathrm{p}=0,629)$. (Tablo 3)

Tablo 3. Modifiye dental anksiyete skalası değerleri açısından yaş grupları arasındaki farklılığa ilişkin analiz sonucu

\begin{tabular}{|c|c|c|c|c|c|c|}
\hline & \multicolumn{4}{|c|}{$\begin{array}{l}\text { Modifiye Dental } \\
\text { Skalasi }\end{array}$} & \multirow{2}{*}{$\begin{array}{c}\begin{array}{c}\text { Analiz } \\
\text { sonucu }\end{array} \\
\mathbf{p}\end{array}$} \\
\hline & & $\mathrm{n}$ & $\underset{\mathbf{n}}{\text { Media }}$ & Min & Max & \\
\hline \multirow{4}{*}{ Yaş } & $\begin{array}{l}17-20 \\
\text { arasi }\end{array}$ & 100 & 10 & 5 & 19 & \multirow{3}{*}{0,629} \\
\hline & $\begin{array}{l}21-25 \\
\text { arası }\end{array}$ & 186 & 10 & 5 & 24 & \\
\hline & $\begin{array}{l}26-30 \\
\text { arasi }\end{array}$ & 14 & 11 & 6 & 22 & \\
\hline & Total & 300 & 10 & 5 & 24 & \\
\hline
\end{tabular}

Modifiye dental anksiyete skalası değerleri bakımından sınıf değişkenine göre istatistiksel olarak anlamlı farklılık bulunmamaktadır ( $\mathrm{p}=0,119)$. (Tablo 4). 
Tablo 4. Modifiye dental anksiyete skalası değerleri açısından sınıflar arasındaki farklılığa ilişkin analiz sonucu

\begin{tabular}{|c|c|c|c|c|c|c|}
\hline & \multicolumn{4}{|c|}{$\begin{array}{c}\begin{array}{l}\text { Modifiye Dental Anksiyete } \\
\text { Skalası }\end{array} \\
\end{array}$} & \multirow{2}{*}{$\begin{array}{c}\begin{array}{c}\text { Analiz } \\
\text { sonucu }\end{array} \\
\mathbf{p}\end{array}$} \\
\hline & & $\mathbf{n}$ & Median & Min & Max & \\
\hline \multirow{6}{*}{ Sinıf } & 1 & 40 & 9 & 5 & 19 & \multirow{5}{*}{0,119} \\
\hline & 2 & 73 & 11 & 5 & 19 & \\
\hline & 3 & 47 & 10 & 5 & 24 & \\
\hline & 4 & 66 & 10 & 5 & 22 & \\
\hline & 5 & 74 & 10 & 5 & 22 & \\
\hline & Toplam & 300 & 10 & 5 & 24 & \\
\hline
\end{tabular}

DMFT Değerleri bakımından cinsiyetler arasında istatistiksel olarak anlamlı farklılık bulunmamaktadır $(\mathrm{p}=0,496)$. (Tablo 5).

Tablo 5. DMFT değerleri açısından cinsiyetler arasındaki farklılığa ilişkin analiz sonucu

\begin{tabular}{|c|l|c|c|c|c|c|c|}
\hline \multicolumn{2}{|c|}{} & \multicolumn{4}{c|}{ DMFT } & \multicolumn{2}{c|}{$\begin{array}{c}\text { Analiz } \\
\text { sonucu }\end{array}$} \\
\cline { 2 - 6 } & $\mathbf{n}$ & Median & Min & Max & z & p \\
\hline \multirow{4}{*}{ Cinsiyet } & Kadın & 123 & 4 & 0 & 14 & & \\
\cline { 2 - 6 } & Erkek & 177 & 4 & 0 & 14 & $-0,681$ & 0,496 \\
\cline { 2 - 6 } & Toplam & 300 & 4 & 0 & 14 & & \\
\hline
\end{tabular}

DMFT Değerleri bakımından yaş grupları arasında istatistiksel olarak anlamlı farklılık bulunmaktadır $(p=0,037)$. (Tablo 6, Şekil 2)

\section{DMFT}

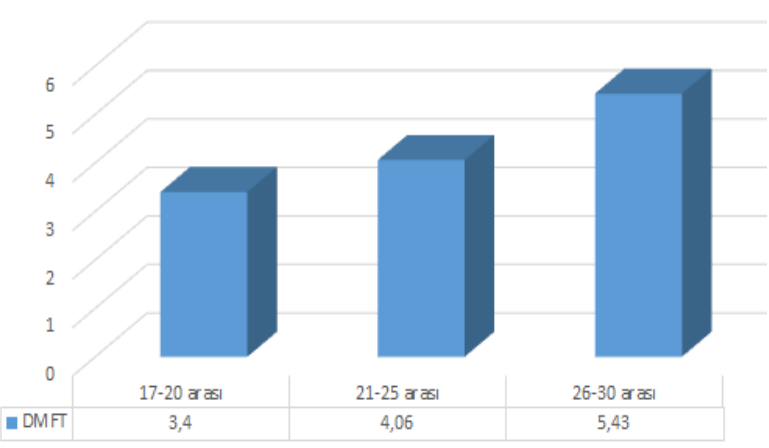

Şekil 2. DMFT değerleri bakımından yaş gruplarına göre dağılım

Tablo 6. DMFT değerleri bakımından yaş grupları arasındaki farklılığa ilişkin analiz sonucu

\begin{tabular}{|l|l|l|l|l|l|l|}
\hline \multicolumn{2}{|c|}{} & \multicolumn{3}{|l}{ DMFT } & Analiz sonucu \\
\cline { 2 - 6 } \multicolumn{2}{c|}{} & $\mathbf{n}$ & Median & Min & Max & $\mathbf{p}$ \\
\hline \multirow{4}{*}{ Yaş } & $\mathbf{1 7 - 2 0}$ arası & 100 & 4 & 0 & 14 & \\
\cline { 2 - 6 } & $\mathbf{2 1 - 2 5}$ arası & 186 & 4 & 0 & 14 & \multirow{2}{*}{$\mathbf{0 , 0 3 7}$} \\
\cline { 2 - 6 } & $\mathbf{2 6 - 3 0}$ arası & 14 & 5,5 & 1 & 10 & \\
\cline { 2 - 6 } & Toplam & 300 & 4 & 0 & 14 & \\
\hline
\end{tabular}

17-20 yaş arasında olanların DMFT değeri 26-30 yaş arasında olanlara göre anlamlı derecede düşüktür.

DMFT değerleri bakımından sınıflar arasında istatistiksel olarak anlamlı farklılık bulunmamaktadır $(\mathrm{p}=0,381)$. (Tablo 7).

Tablo 7. DMFT değerleri bakımından sınıflar arasındaki farklılığa ilişkin analiz sonucu

\begin{tabular}{|l|l|l|l|l|l|c|}
\hline \multicolumn{2}{|c|}{} & \multicolumn{3}{l}{ DMFT } & Analiz sonucu \\
\cline { 2 - 6 } & n & Median & Min & Max & p \\
\hline \multirow{5}{*}{ Sinıf } & $\mathbf{1}$ & 40 & 3 & 0 & 14 & \\
\cline { 2 - 6 } & $\mathbf{2}$ & 73 & 4 & 0 & 14 & \multirow{2}{*}{0,381} \\
\cline { 2 - 6 } & $\mathbf{3}$ & 47 & 3 & 0 & 14 & \\
\cline { 2 - 6 } & $\mathbf{4}$ & 66 & 4 & 0 & 12 & \\
\cline { 2 - 6 } & $\mathbf{5}$ & 74 & 4 & 0 & 12 & \\
\cline { 2 - 6 } & Toplam & 300 & 4 & 0 & 14 & \\
\hline
\end{tabular}

DMFT değerleri bakımından MDAS sınıfları arasında istatistiksel olarak anlamlı farklılık bulunmamaktadır $(\mathrm{p}=0,500)$. (Tablo 8).

Tablo 8. DMFT değerleri bakımından MDAS sınıfları arasındaki farklılığa ilişkin analiz sonucu

\begin{tabular}{|c|c|c|c|c|c|c|}
\hline & \multicolumn{4}{|c|}{ DMFT } & \multirow{2}{*}{$\begin{array}{c}\begin{array}{c}\text { Analiz } \\
\text { sonucu }\end{array} \\
\mathbf{p}\end{array}$} \\
\hline & & $\mathbf{n}$ & Median & Min & Max & \\
\hline \multirow{4}{*}{$\begin{array}{l}\text { MDAS } \\
\text { SINIF }\end{array}$} & $\begin{array}{lcc}\text { M1 (5 ve } \\
\text { daha az) }\end{array}$ & 19 & 2 & 0 & 9 & \multirow{3}{*}{0,5} \\
\hline & $\begin{array}{ll}\text { M2 } & (5-19 \\
\text { arası) }\end{array}$ & 266 & 4 & 0 & 14 & \\
\hline & $\begin{array}{l}\text { M3 (19 ve } \\
\text { daha fazla) }\end{array}$ & 15 & 4 & 0 & 9 & \\
\hline & Toplam & 300 & 4 & 0 & 14 & \\
\hline
\end{tabular}

Bütün yaş gruplarına bakıldığında, Modifiye dental anksiyete skalası değerleri ile DMFT değerleri arasında istatistiksel olarak anlamlı bir ilişki olmadığı görülmektedir. ( $\mathrm{p}>0,05)$. (Tablo 9).

Tablo 9. MDAS değerleri ile DMFT değerleri arasındaki ilişkiye dair analiz sonucu

\begin{tabular}{|l|l|c|c|}
\hline \multicolumn{2}{|c}{ Yaş } & DMFT \\
\hline \multirow{2}{*}{$\mathbf{1 7 - 2 0}$ arası } & \multirow{2}{*}{ Modifiye dental anksiyete skalası } & $\mathbf{~}$ & $-0,154$ \\
\cline { 3 - 5 } & & $\mathbf{n}$ & 0,127 \\
\hline \multirow{2}{*}{$21-25$ arası } & \multirow{2}{*}{ Modifiye dental anksiyete skalası } & $\mathbf{p}$ & 100 \\
\cline { 3 - 5 } & & $\mathbf{n}$ & 186 \\
\hline \multirow{2}{*}{ 26-30 arası } & Modifiye dental anksiyete skalası & $\mathbf{p}$ & 0,844 \\
\cline { 3 - 5 } & & $\mathbf{n}$ & 14 \\
\hline \multirow{2}{*}{ Toplam } & Modifiye dental anksiyete skalası & $\mathbf{n}$ & $-0,033$ \\
& & & \\
\hline
\end{tabular}




\section{TARTIŞMA}

Günümüz klinik pratiğinde yaşanan teknolojik gelişmeler ve etkin ağrı kontrolü sağlayan tekniklere rağmen; dental anksiyete varlığını sürdürerek oral hijyen ve hayat kalitesi üzerinde olumsuz etki yaratmaya devam etmektedir. Bu nedenle çeşitli ülkelerden birçok araştırmacı, toplumun farklı yaş ve meslek gruplarını içeren anksiyete çalışması yapmayı sürdürmektedir (15-20). Hastalara yönelik yapılan çok sayıda çalışma bulunmasına rağmen diş hekimliği fakültesi öğrencilerini sınıf değişkenini de baz alarak kendi aralarında değerlendiren ve anksiyete düzeyinin ağız-diş sağlığı ile ilişkisini inceleyen kısıtlı sayıda çalışma mevcuttur. Buradan hareketle planlanan bu çalışma kapsamında, lisans boyunca yoğun bir eğitim sürecinden geçen diş hekimliği fakültesi öğrencilerinin bireysel anksiyete düzeyleri ile diş sağlığı arasındaki korelasyonunun araştırılması hedeflenmiştir.

Çalışmamıza katılan 300 öğrenciye anksiyete düzeylerini ölçebilmek için Modifiye Dental Anksiyete Skalası (MDAS) anket formunda sunulmuştur. İngiltere'de 1392 bireyin katılımıyla yapılan bir araştırmada bu skalanın; yüksek ve düşük anksiyete düzeyine sahip bireylerde yüksek geçerlilik ve ciddi güvenilirliğe sahip olduğu ifade edilmiştir (24). Türkiye'de yapılan benzer çalışmalar sonucunda da bu skalanın güvenilir ve geçerli olduğu bildirilmiştir $(25,26)$.

Çalışmamızda yer alan kadın katılımcıların erkeklere oranla anlamlı derece yüksek anksiyete düzeyine sahip olduğu sonucuna ulaşılmıştır. Rusya'da yapılan 2018 tarihli benzer çalışmada da bizim araştırmamızla uyumlu veriler elde edilmiştir (27). Finlandiya'da 2016'da yapılan aynı konulu çalışmada da kadın katılımcılarda yüksek anksiyete rapor edilmiştir (28).

Yaptığımız çalışmada yaş ve sınıf değişkenleri istatistiksel olarak incelendiğinde ise, dental anksiyete ile anlamlı bir ilişki olmadığı sonucuna ulaşılmıştır. 2013'te Türkiye'de yapılan ve diş hekimliği öğrencilerini kapsayan çalışmada ankete katılım sağlayan 1. sınıf ögrencilerinde 5. Sinıflara nazaran anlamlı seviyede yüksek anksiyete saptandığı ifade edilmiştir (29). Bu sonuçlar bizim verilerimizle uyuşmamaktadır.

Çalışmamız sırasında katılımcıların muayenesi ile elde edilen DMF-T verileri cinsiyet ve sınıf değişkenleri ile bir korelasyon göstermemesine rağmen yaş ile anlamlı derecede farklılık göstermiştir. 17-20 yaş aralığında olanların DMF-T değeri 26-30 yaş aralığındakilere nazaran anlamlı derecede düşük çıkmıştır. Türkiye'de yapılan benzer çalışmada ise yaş ile DMF-T indeksi arasında anlamlı farklılık bulunamadığı bildirilmiştir (30). Bu sonuçlar, çalışmamızdan elde edilen verilerle çelişmektedir.

Çalışmamızın dental anksiyete düzeyi ile DMF-T arasındaki korelasyonunun incelendiği son bölümünde ise, elde edilen verilerden hareketle DMF-T değerleri ile dental anksiyete arasında anlamlı bir farklılık olmadığ sonucuna ulaşılmıştır. Literatürde dental anksiyete düzeyleri ile DMF-T indeksini karşılaştıran bir dizi çalışma mevcuttur. Taani (31) ve Eitner (32) birbirlerinden bağımsız yaptıkları araştırmada dental anksiyete ve DMF-T indeksi arasında anlamlı bir ilişki olmadığını bildirmiştir. Schuller (33) de yaptığı benzer çalışmada yüksek ve düşük anksiyete düzeyine sahip bireyler arasinda DMF-T indeksinde anlamlı bir fark bulunmadığını ifade etmiştir. Tüm bu çalışma sonuçları, topladığımız verilerden elde edilen sonuçlarla paralellik göstermektedir.

\section{SONUÇ}

Diş hekimliği fakültesinde eğitim gören öğrencilerin DMF-T değerlerinin toplum geneline göre daha düşük olması beklenirken üst sınıflara gidildikçe bu değerlerin anksiyete verilerinden bağımsız olarak arttığı görülmektedir. Çürüğün multifaktöriyel bir hastalık olmasının bu sonuçlarda etkili olduğunu düşünmekteyiz. Araştırmamızdan elde edilen diğer verilere göre; kadın diş hekimliği fakültesi öğrencileri erkek öğrencilere oranla anlamlı derecede yüksek anksiyeteye sahip bulunmuştur. Cinsiyet ve sınıftan bağımsız olarak diş hekimliği eğitiminin erken bir aşamasında müfredata eklenebilecek '"anksiyete tanı ve kontrol yöntemleri', üzerine bir eğitimin kaygı seviyelerini azaltmada yardımcı olacağını düşünmekteyiz. Özellikle eğitimlerinin klinik aşamasına geçmeden önce öğrencileri, kaygılı hastaya yaklaşım ve onun motivasyonunu konusunda donanımlı hale getirmek, doğru eğitim, açık iletişim ve uygun yönlendirme ile hastanın kaygısının azaltılarak motivasyonunu arttırılması sağlanabilir. $\mathrm{Bu}$ şartların sağlanması klinik başarıyı arttıracaktır.

Yazarların Katkıları: Fikir/Kavram: E.P.B.; Tasarım: E.P.B.; Veri Toplama: E.P.B.; Analiz ve Yorum: S.G.; Literatür Taraması: S.G.; Makale Yazımı: Ş.B.; Eleştirel İnceleme: Ş.B.

\section{KAYNAKLAR}

1. Akarslan ZZ, Erten H. Diş hekimliği korkusu ve kaygısı. Hacettepe Diş Hek Fak Derg. 2009; 33(1): 62-8.

2. Armfield JM, Spencer AJ, Stewart JF. Dental fear in Australia: who's afraid of the dentist? Aust Den J. 2006; 51(1): 78-85.

3. Locker D, Liddell AM. Correlates of dental anxiety among older adults. J Dent Res. 1991; 70(3): 198-203.

4. Thomson WM, Stewart JF, Carter KD, Spencer AJ. Dental anxiety among Australians. Int Dent J. 1996; 46(4): 320-4.

5. Armfield JM, Stewart JF, Spencer AJ. The vicious cycle of dental fear: exploring the interplay between oral health, service utilization and dental fear. BMC Oral Health. 2007; 7(1): 1-15.

6. Boyle CA, Newton T, Milgrom P. Who is referred for sedation for dentistry and why? Br Dent J. 2009; 206(6): 322-3.

7. Smith TA, Heaton LJ. Fear of dental care: are we making any progress? J Am Dent Assoc. 2003; 134(8): 1101-8.

8. Armfield JM. The extent and nature of dental anxiety and phobia in Australia. Aust Den J. 2010; 55(4): 368-77.

9. Firat D, Tunc EP, Sar V. Dental anxiety among adults in Turkey. J Contemp Dent Pract. 2006; 7(3): 75-82.

10. Tunc EP, Firat D, Onur OD, Sar V. Reliability and validity of the modified dental anxiety scale (MDAS) in a Turkish population. Community Dent Oral Epidemiol. 2005; 33(5): 357-62. 
11. Muğlalı M, Kömerik N. Ağız cerrahisi ve anksiyete. CÜ Diş Hek Fak Derg. 2005; 8(2): 83-8.

12. Kanegane K, Penha SS, Munhoz CD, Rocha RG. Dental anxiety and salivary cortisol levels before urgent dental care. J Oral Sci. 2009; 51(4): 515-20.

13. Nicolas E, Collado V, Faulks D, Bullier B, Hennequin M. A national cross-sectional survey of dental anxiety in the French adult population. BMC Oral Health. 2007; 7(1): 12.

14. Caltabiano ML, Croker F, Page L, Sklavos A, Spiteri J, Hanrahan L. et al. Dental anxiety in patients attending a student dental clinic. BMC Oral Health. 2018; 18(1): 48.

15. Thomson WM, Locker D, Poulton R. Incidence of dental anxiety in young adults in relation to dental treatment experience. Community Dent Oral Epidemiol. 2000; 28(4): 289-94.

16. De Jongh A, Adair P, Meijerink-Anderson $\mathrm{M}$. Clinical management of dental anxiety: what works for whom? Int Dent J. 2005; 55(2): 73-80.

17. Bergdahl M, Bergdahl J. Temperament and character personality dimensions in patients with dental anxiety. Eur J Oral Sci. 2003; 111(2): 93-8.

18. Erten H, Akarslan ZZ, Bodrumlu E. Dental fear and anxiety levels

of patients attending a dental clinic. Quintessence Int. 2006; 37(4): 304-10.

19. Serra-Negra J, Paiva SM, Oliveira M, Ferreira E, Freire-Maia F, Pordeus I. Self-reported dental fear among dental students and their patients. Int J Environ Res Public Health. 2012; 9(1): 44-54.

20. Shaikh MA, Kamal A. Over dental anxiety problems among university students: perspective from Pakistan. J Coll Physicians Surg Pak. 2011; 21(4): 237-8.

21. Cesar J, de Moraes AB, Milgrom P, Kleinknecht RA. Cross validation of a Brazilian version of the dental fear survey. Community Dent Oral Epidemiol. 1993; 21(3): 148-50.

22. Yüzügüllü B, Gülşahı A, Çelik Ç, Bulut Ş. Klinik öncesi diş hekimliği öğrencilerinin dental anksiyete düzeylerinin belirlenmesi. Ondokuz Mayıs Üniv. Diş Hekimliği Derg. 2009; 10(3): 106-10.

23. Al-Omari WM, Al-Omiri MK. Dental anxiety among university students and its correlation with their field of study. Journal of Applied Oral Science. 2009; 17(3): 199-203.

24. Humphris GM, Morrison T, Lindsay SJ. The modified dental anxiety scale: validation and United Kingdom norms. Community Dent Health. 1995; 12(3): 143-50.

25. Tunc EP, Firat D, Onur OD, Sar V. Reliability and validity of the modified dental anxiety scale (MDAS) in a Turkish population. Community Dent Oral Epidemiol. 2005; 33(5): 357-62.

26. Ilgüy D, Ilgüy M, Dinçer S, Bayirli G. Reliability and validity of the modified dental anxiety scale in Turkish patients. J Int Med Res. 2005; 33(2): 252-9.

27. Drachev SN, Brenn T, Trovik TA. Prevalence of and factors associated with dental anxiety among medical and dental students of the Northern State Medical University, Arkhangelsk, North-West Russia. Int J Circumpolar Health. 2018; 77(1): 1454786.

28. Pohjola V, Rekola A, Kunttu K, Virtanen JI. Association between dental fear and oral health habits and treatment need among university students in Finland: a national study. BMC Oral Health. 2016; 16(1): 1-9.

29. Ergüven SS, Işık B, Kılınç Y. Diş hekimliği fakültesi birinci sınıf öğrencileri ile son sınıf öğrencilerinin dental kayg1-korku düzeylerinin karşılaştırmalı olarak değerlendirilmesi. Acta Odontol Turc. 2013; 30(2): 70-6.

30. Arslan S, Ülker M, Elmalı F, Öztürk A, Günay O. Diş hekimliği fakültesi öğrencilerinde çürük prevelansı, ağı diş sağlığı tutum ve davranışları ve dental anksiyetenin belirlenmesi. AÜ Diş Hek. Fak. Derg. 2008; 35(2): 53-60.

31. Taani DQ, El-Qaderi SS, Abu Alhaija ES. Dental anxiety in children and its relationship to dental caries and gingival condition. Int J Dent Hyg. 2005; 3(2): 83-7.

32. Eitner S, Wichmann M, Paulsen A, Holst S. Dental anxiety-an epidemiological study on its clinical correlation and effects on oral health. J Oral Rehabil. 2006; 33(8): 558-93.

33. Schuller AA, Willumsen T, Holst A. Are there differences in oral health and oral health behaviour between individuals with high and low dental fear? Community Dent Oral Epidemiol. 2003; 31(2): 11621. 